\section{BOOK REVIEW}

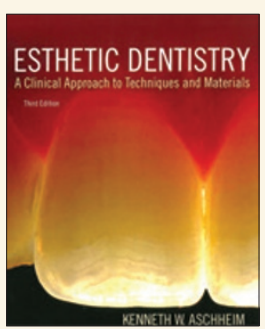

ESTHETIC DENTISTRY: A CLINICAL APPROACH TO TECHNIQUE AND MATERIALS, 3RD EDITION

K. W. Aschheim

Elsevier

price £164; pp 576

ISBN 9780323091763

Esthetic Dentistry is the third edition of this clinical guide, first published 20 years ago. It is divided into six key parts exploring themes of the principles of aesthetics, materials and techniques as well as non-clinical guidance on practice management and social hurdles related to the patient seeking aesthetic dentistry.

Part one begins with a troubleshooting guide acting as a reference for the book's chapters, whereby the reader can identify page numbers to access information about difficulties they may encounter. Part one is divided into tooth-related problems including management of tooth surface loss and misaligned or malformed teeth, periodontal problems, facial contouring, skeletal discrepancies and dermatological problems.

Part two focuses on the principles of aesthetics, reviewing the history behind smile design and biometrics. Parts three and four revisit the fundamentals of dental materials and demonstrate the clinical applications of indirect and direct restorations. Chapters on the use of direct and indirect restorations provide comprehensive guidance on managing common clinical encounters and methods to avoid pitfalls such as postoperative sensitivity. The textbook covers advanced clinical practice, including implant surgery, as well as identifying the limitations of restorative practice whereby maxillofacial surgery may be more appropriate to manage dento-facial anomalies that cannot be corrected without invasive head and neck surgery.

Parts five and six complete the psycho-social approach used by this book exploring how to effectively market aesthetic services whilst abiding by legal and ethical principles to avoid litigation; as well as management of patients with dental disease secondary to psychiatric disorders.

This evidence-based textbook is an excellent guide suitable for all clinicians managing patients striving for aesthetic outcomes. The broad ranges of topics covered allow the reader to approach problems in a holistic manner in an easily readable format, whilst providing straightforward clinical solutions.

Z. MIRZA

\section{ERRATUM}

Book review Br Dent J 2015; 219: 55

In the above book review the author was incorrectly printed as P. Schogger. The correct author of the book review is T. Hughes.

We apologise for any inconvenience caused.

\title{
PARENTAL KNOWLEDGE GAP LEAVING NHS WITH £22M EARLY DENTAL CARE BILL
}

New research has revealed how a lack of understanding amongst parents on the importance of early dental care is leaving the NHS with an estimated $£ 22 \mathrm{~m}$ annual bill.

The survey of over 2,000 UKbased parents carried out by My Dentist highlights how dental disengagement has left over one million children aged eight and under still waiting for their first trip to the dentist. Additionally, over 700,000 children who have been to the dentist have had at least one filling, each at a cost of $£ 31$ to the Department of Health.

These findings demonstrate an urgent need for more initiatives for educating and engaging parents and their children on oral health and the importance of looking after their teeth properly from a young age.

Many parents failed to take their children to the dentist early enough with 57\% of respondents not going until after their furst birthday, considerably later than when teething starts, despite almost 50\% reporting no barriers to doing so earlier. Furthermore, only a quarter $(26 \%)$ of children brush their teeth for the recommended two minutes per session.

The survey also highlighted how lack of dental engagement may be contributing to parental confusion around positive factors for oral health and free treatments available on the NHS:

- 20\% incorrectly thought that fruit smoothies were good for their child's teeth

- $20 \%$ incorrectly believe that sippy cups are good for their child's teeth

- 1 in 8 parents (13\%) incorrectly said fluoride is bad for their child's teeth

- Nearly a third (31\%) were unaware of free NHS treatments available to kids such as fluoride varnishing

Commenting, Barry Cockcroft, Former Chief Dental Officer for NHS England and Non-Executive Director at My Dentist, said: 'Early dental care can be a confusing, daunting issue for many parents. As an industry we must work harder to ensure the best and most appropriate resources are available. Better education must support the significant access improvements the industry and its relevant stakeholders are making, in order to build a system where the key drivers of prevention and treatment can work effectively together.'

\section{CALLING ALL DENTAL WRITERS - NEW WRITER'S DAY}

Places are still available on the one day course for new writers to be held at the BDA on Tuesday 8 September 2015. The course, run by the British Dental Editors' Forum and sponsored by the $B D J$, will include how to write and submit papers and articles to peer reviewed journals; the peer review process, publication ethics, plagiarism, how to follow journal guidelines and the increasing role of social media in the publishing process.

The cost is $£ 40$ per person which includes lunch, and participants will be welcome to stay on into the early evening for a reception and presentation of the BDIA-sponsored Young Communicator of the Year Award.

Further details are available by emailing Stephen Hancocks, Editor-in-Chief, BDJ on s.hancocks@bda.org.

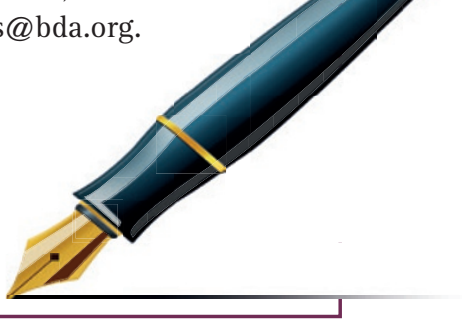

